\title{
The Ultrastructure, Kinetics and Intralobular Distribution of Apoptotic Hepatocytes after Portal Branch Ligation with Special Reference to Their Relationship to Necrotic Hepatocytes
}

\author{
Kazuo IKEDA ${ }^{1,2}$, Hiroaki KINOSHITA ${ }^{2}$, Kazuhiro HiroHASHI ${ }^{2}$, Shoji KuBO ${ }^{2}$ and Kenji KANEDA ${ }^{1}$ \\ Departments of Anatomy ${ }^{1}$ and Surgery ${ }^{2}$, Osaka City University Medical School, Osaka, Japan
}

Received December 3, 1994

\begin{abstract}
Summary. Apoptosis was originally defined as shrinkage necrosis, as a distinct mode of cellular death from coagulative necrosis in the rat liver lobes after portal branch ligation. To reveal the functional role of the apoptosis of hepatocytes in the volume reduction and recovery of normal hepatic architecture in portaldeprived liver lobes, we ligated the portal vein branch supplying the left and median liver lobes in Wistar rats. The liver lobes were perfusion-fixed with glutaraldehyde solution via the proximal site of the ligated portion of the portal vein on Days 1, 2, 4, 7 and 14 after operation and examined light and electron microscopically. On Day 2 after ligation, massive necrosis of hepatocytes occurred in the central to intermediate zones of the liver lobule, and apoptotic hepatocytes were observed in the boundary region between necrotic and normal areas. Such necrotic area-associated apoptosis of hepatocytes was most frequent on Day 2, declining thereafter. The sequential changes of the cell organelles in apoptotic hepatocytes were distinct from those in necrotic hepatocytes. On Day 7, when necrotic areas had almost disappeared the apoptosis of hepatocytes occurred mostly between intact hepatocytes in the "combined hepatic cell cords" which included no obvious sinusoidal lumen between hepatic cell cords. Such necrotic area-nonassociated apoptosis began to increase in frequency on Day 4, reached a peak on Day 7 and was gone by Day 14, when normal hepatic architecture was recovered. The present study suggests that both necrotic area-associated and non-associated apoptosis of hepatocytes may be induced by mild ischemia and contribute in part to the volume reduction of ligated liver lobes. It further reveals that the necrotic area-non-associated apoptosis of hepatocytes plays a role in reconstructing the architecture of hepatic cell cords after necrotic hepatocytes have undergone dissolution in the liver lobule.
\end{abstract}

The ligation of a branch of the portal vein in different animal species-including rats-induces atrophy of ligated liver lobes via multifocal necroses and compensatory hypertrophy of non-ligated lobes (STEINER and MARTINEZ, 1961). KERR (1965) reported that another mode of cellular death distinct from coagulative necrosis, occurred in the portal-deprived liver lobes of i.e., "shrinkage necrosis" in the hepatocytes. Since shrinkage necrosis was found outside the patches of coagulative necrosis, he surmised that very severe cell damage resulted in coagulative necrosis, while moderate damage induced shrinkage necrosis and that

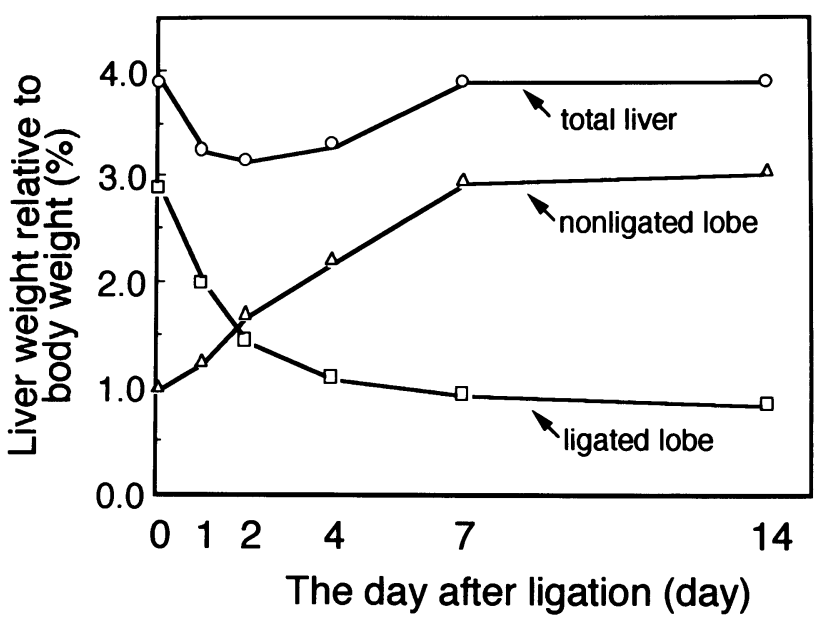

Fig. 1. Time course of weight changes in the total liver, non-ligated liver lobes and ligated liver lobes after ligation of the portal vein branches supplying the left and median lobes of the rat liver. Three to five animals were used at each time period. 

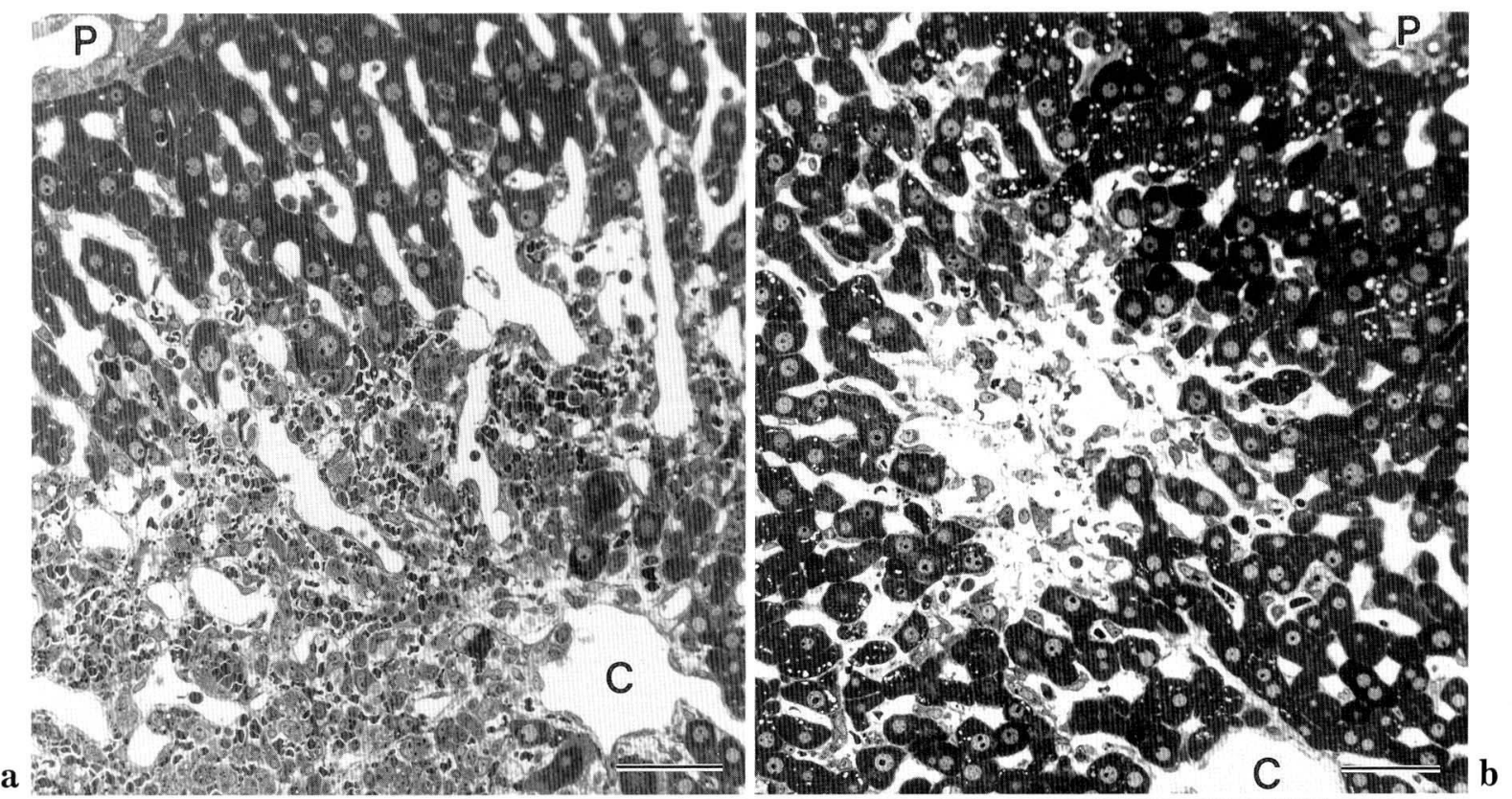

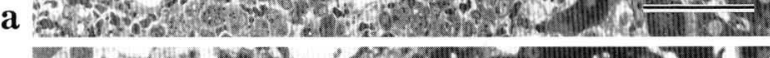

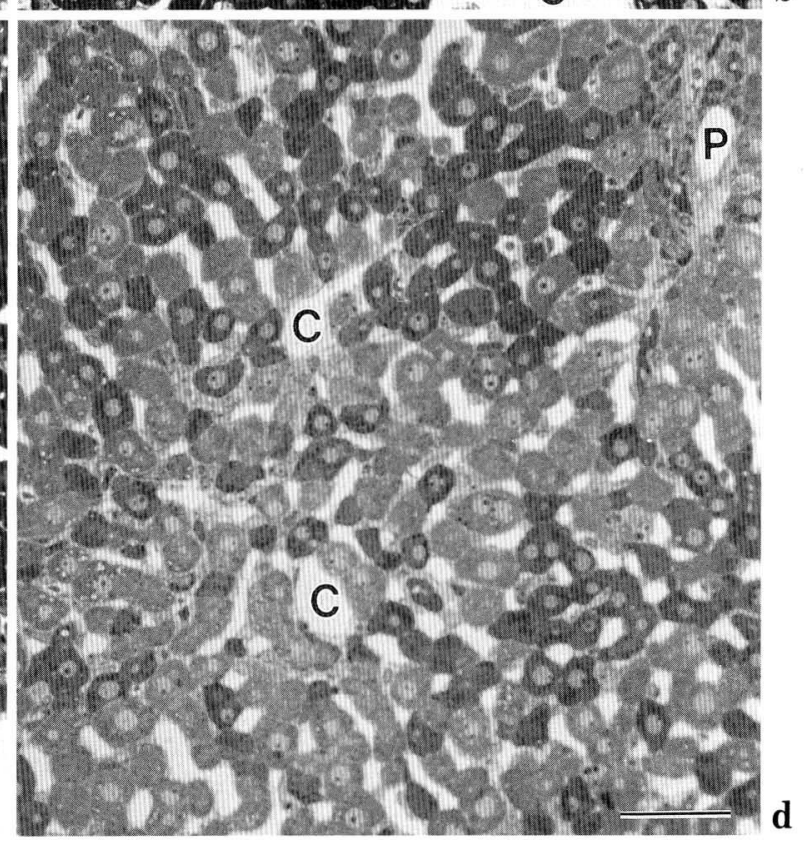

c
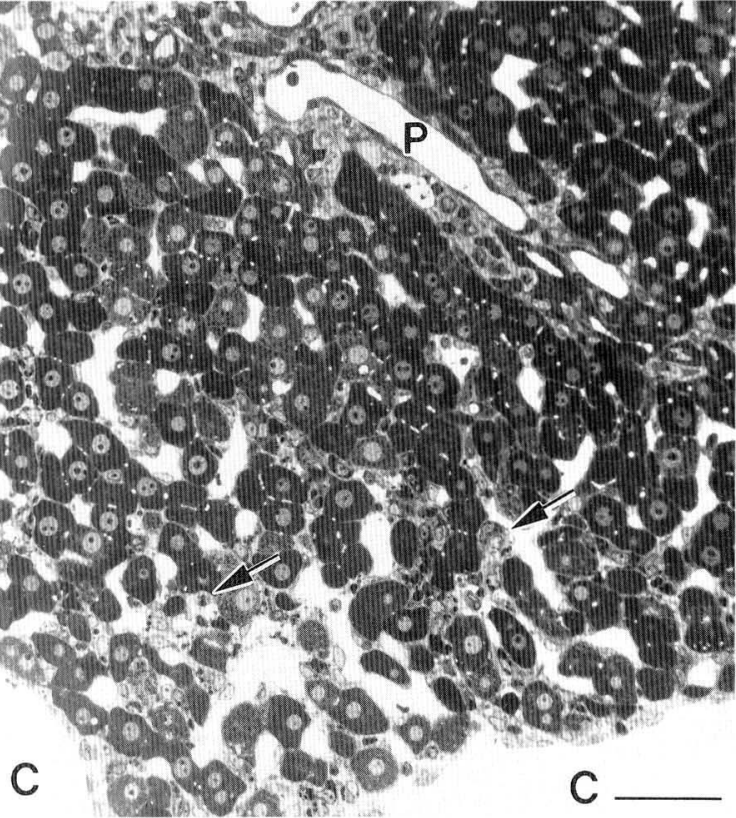

Fig. 2. Histological changes in ligated liver lobes after portal branch ligation. a. Two days after operation, a wide necrotic area is seen near the central vein $(C)$. Several hepatocytes around the central vein, however, remain intact. Necrotic hepatocytes in the necrotic area have already been removed by extrasinusoidally migrating macrophages. Sinusoidal lining cells are viable and maintain the structure of the sinusoid. b. On Day 4, the necrotic area has become reduced in size and shows an obscure sinusoidal structure. c. On Day 7, the necrotic area (arrows) is very small, but still separates hepatic cords. d. On Day 14, normal hepatic architecture has been recovered. $C$ central veins, $P$ portal veins. Toluidine blue-staining. Bars $(\mathrm{a}-\mathrm{d})=50 \mu \mathrm{m}$ 


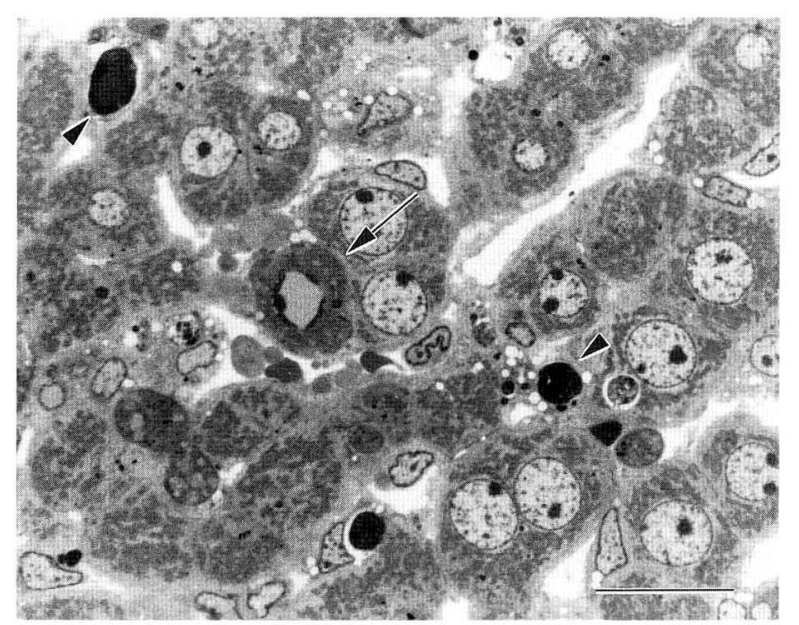

Fig. 3. Apoptosis of hepatocytes in ligated liver lobes on Day 7. Apoptotic hepatocytes exhibit nuclear chromatin condensation (arrow) or apoptotic bodies (arrowheads). Toluidine blue-staining. Bar $=20 \mu \mathrm{m}$

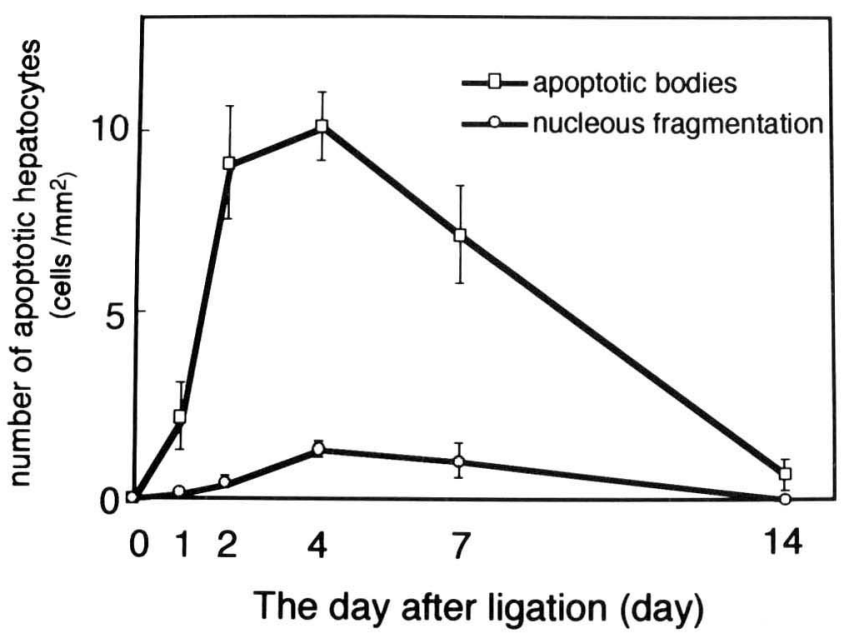

Fig. 4. Time course of the incidence of apoptotic hepatocytes (cell number per unit square of sections) in ligated liver lobes. Ten sections from 3-5 rats were examined at each time period. Bars indicate standard deviation.

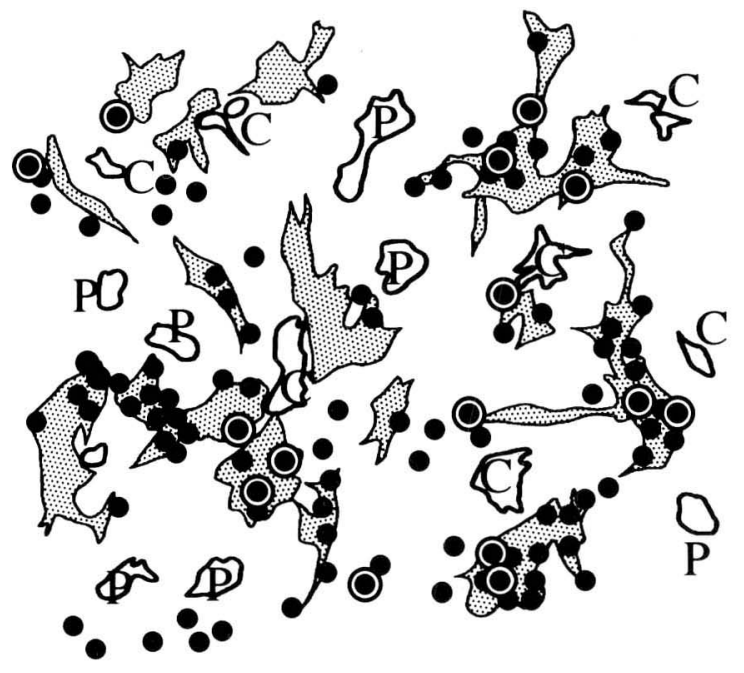

Fig. 5. Diagram showing the distribution of apoptotic hepatocytes in ligated lobes on Day 4. Apoptotic cells were plotted on the photographs of $0.5 \mu \mathrm{m}$-thick toluidine blue-stained sections. Five adjacent sections were then overlayered. Double-circle indicates an apoptotic cell with nuclear chromatin condensation; closed circle indicates an apoptotic cell which shows apoptotic bodies. Dotted por tions indicate necrotic areas. $P$ portal veins, $C$ central veins. the elimination of hepatocytes but also the reconstruction of hepatic cords after removing damaged cells. Recently, embolization of the portal vein branches both types of cellular death contributed to the atrophy of ischemic liver lobes. He demonstrated more clearly the participation of shrinkage necrosis in organ and median liver lobes where shrinkage necrosis occurs without necrosis (KERR, 1971). RozGA et al. (1986), however, reevaluated the experimental model of portal branch ligation in the rat and showed that variable Shrinkage necrosis reported on morphological grounds was later renamed apoptosis because it was revealed to have an important biological role in tissue animals under both physiological and pathological conditions (KERR et al., 1972).

The ultrastructure of apoptotic hepatocytes and fate have been examined in detail (KERR, 1971), but there has been little date on the difference of the functional significance between apoptosis and necrosis in the process of liver atrophy. Although liver lobules of the atrophic liver become smaller usual due to the massive loss of hepatocytes (SCHALm et al., 1956), they recover normal hepatic architecure (KERR, 1971). This process therefore includes not only 


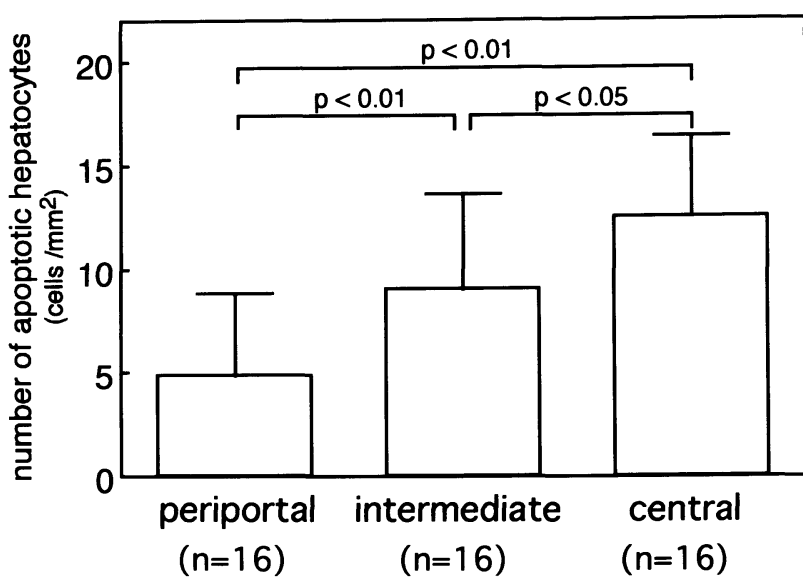

Fig. 6. Incidence of apoptotic hepatocytes in periportal, intermediate and central areas of the liver lobule per unit square of each area 4 days after ligation.
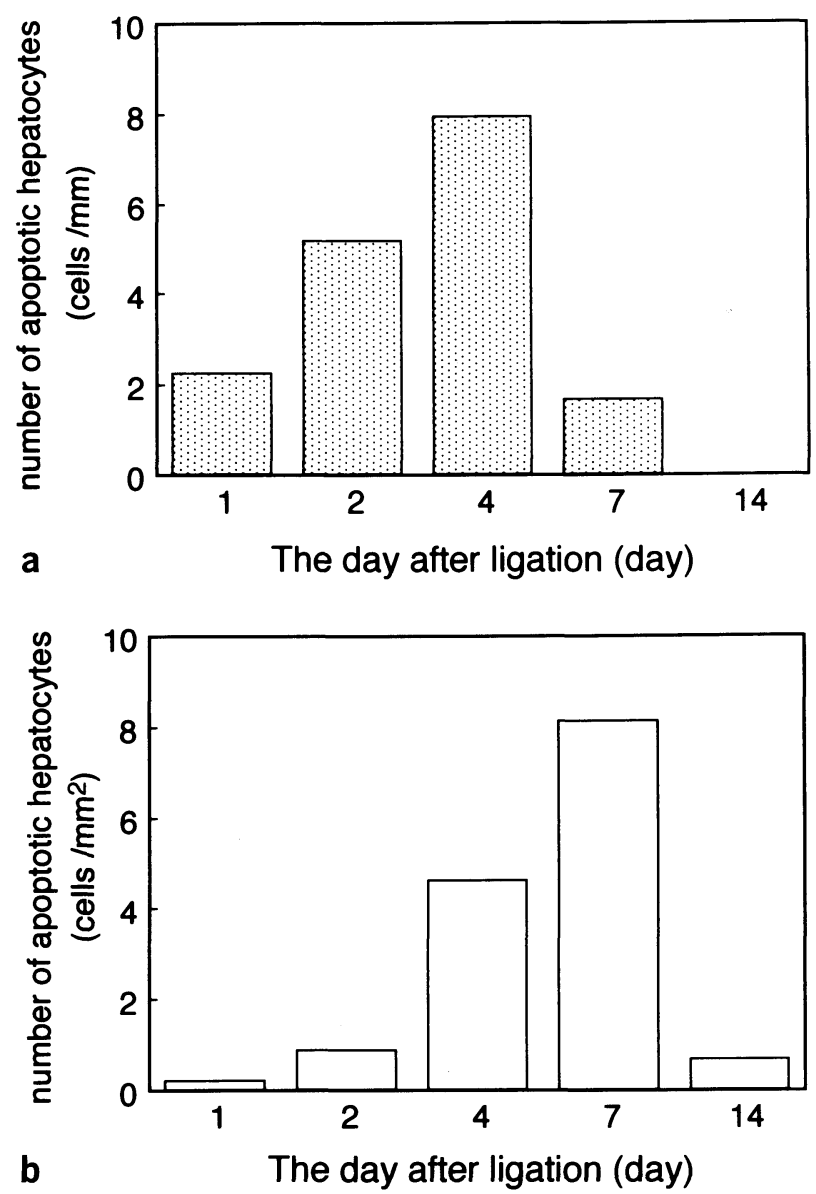

Fig. 8 a. Incidence of apoptotic hepatocytes in necrotic areas expressed as the number per unit length of the circumference of necrotic foci in ligated liver lobes. b. Incidence of apoptotic hepatocytes in non-necrotic areas expressed as the number per unit square of non-necrotic areas.

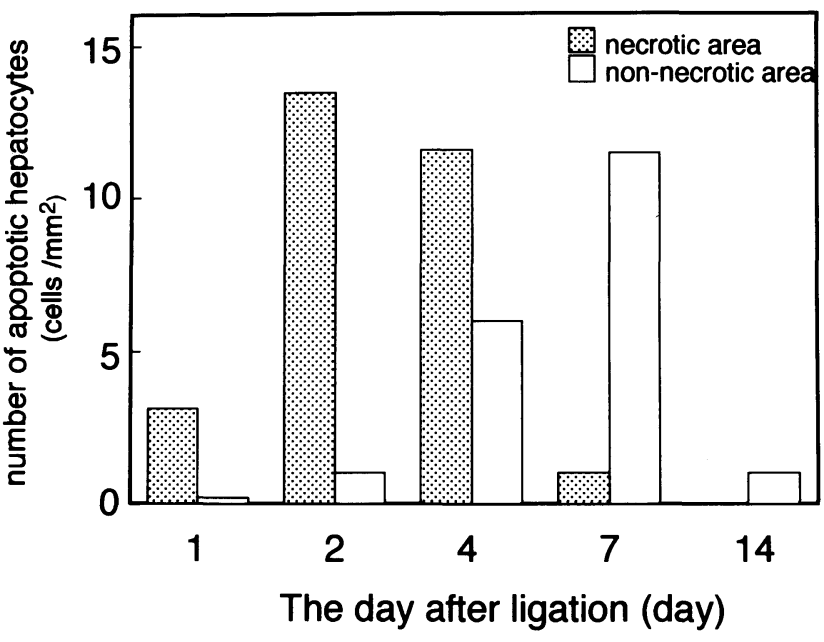

Fig. 7. Incidence of apoptotic hepatocytes in necrotic and non-necrotic areas expressed as the number of cells per unit square of the whole area.

which supply tumor-bearing liver lobes has come to be often performed prior to surgical resection of a hepatocellular carcinoma in order to reduce the portion requiring resection and compensatorily enlarge the non-resected portion. This technique has yielded good clinical results (KINOSHITA et al., 1986, 1992). It is therefore clinically important as well to elucidate the histological events occurring in the process of atrophy of portal-deprived liver lobes.

In order to determine the functional role played by apoptosis of hepatocytes in the process of weight reduction of the liver in comparison with that of necrosis, we have here used a rat model of portal branch ligation of the liver where both types of cellular death take place in the same specimen, and examined the time course and incidence of apoptosis of hepatocytes and the relationship between apoptosis and necrotic foci in the ligated liver lobes.

\section{MATERIALS AND METHODS}

\section{Animals}

Male Wistar rats $(220-280 \mathrm{~g})$ were purchased from Clea Inc. (Shizuoka, Japan), housed at a constant temperature and fed standard chow pellets and water ad libitum. All experiments were performed in accordance with the standard guidelines for animal experiments of Osaka City University. 

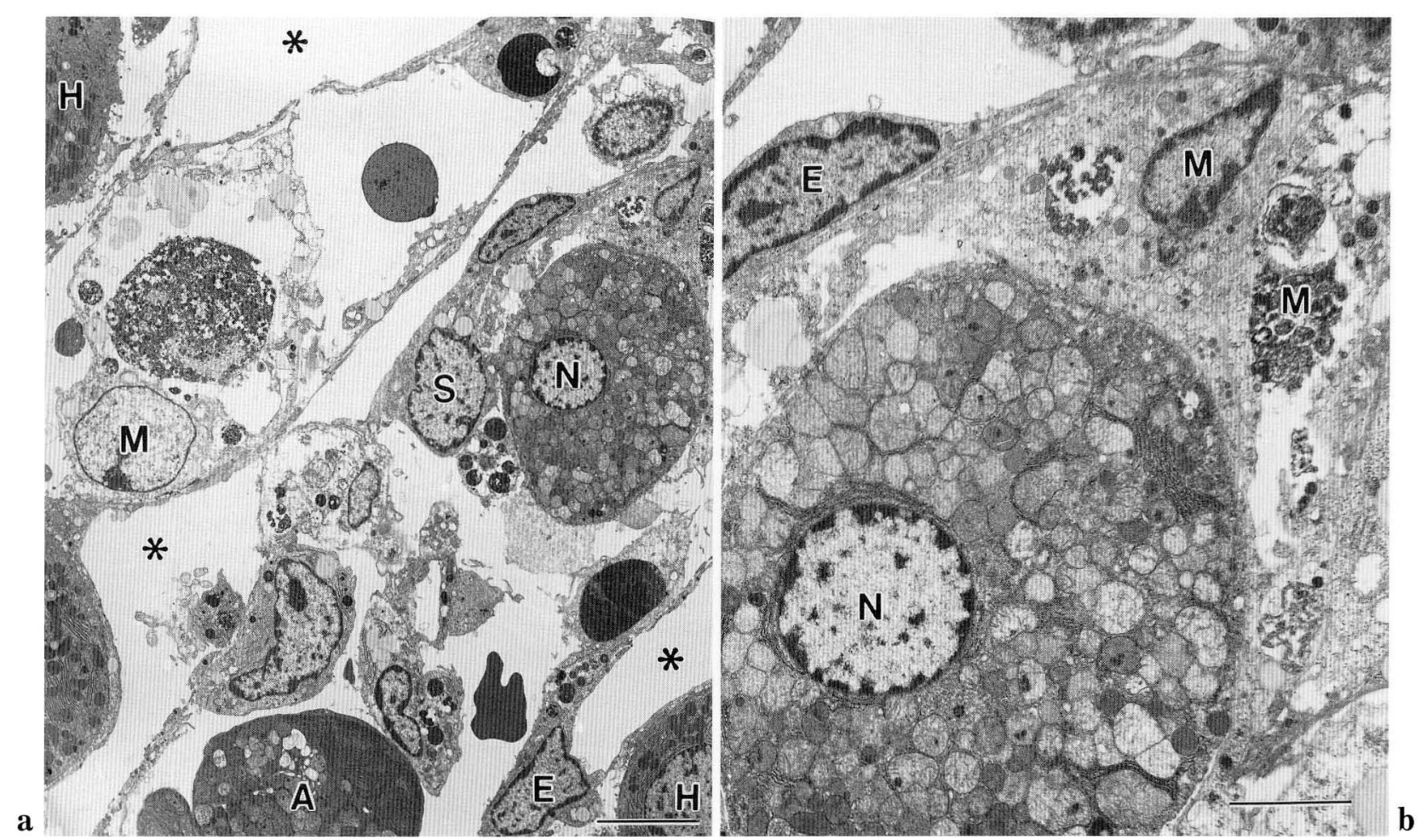

Fig. 9 a. Portion of the boundary between necrotic areas and normal areas 2 days after ligation. Hepatocytes undergo necrosis $(N)$ and apoptosis $(A)$. Macrophages $(M)$ exit the sinusoid and phagocitize them. They become poor in cytoplasmic matrix and may be undergoing degeneration. Sinusoidal lining cells such as endothelial cells $(E)$ and perisinusoidal stellate cells $(S)$ are intact. Asterisks sinusoids, $H$ intact hepatocytes. Bar $=10 \mu \mathrm{m}$. b. Macrophages $(M)$ extend their cytoplasmic projections around a necrotic hepatocyte $(N)$ which exhibits normal features of nucleus and swelling of mitochondria. $E$ endothelial cells. Bar $=3 \mu \mathrm{m}$

\section{Ligation of a portal vein branch}

Under ether anesthesia, the abdomen was opened. The branch of the portal vein which fed the left and median lobes of the liver was ligated with sutures at the portion immediately after the branch to the right lobes emerged, with care taken not to injure the accompanying hepatic artery and bile duct. Three to five animals were sacrificed each on Days 1, 2, 4, 7 and 14 after ligation. The ligated and non-ligated liver lobes were weighed. The relative weight of ligated lobes or non-ligated lobes to the body weight was then calculated and expressed by percentage.

\section{Light and electron microscopy}

Under ether anesthesia, a $21 \mathrm{G}$ cannula was inserted into the proximal portion of the ligated portion of the portal vein. The ligated liver lobes were perfused first with saline and then with $1.5 \%$ glutaraldehyde in $0.062 \mathrm{M}$ cacodylate buffer, $\mathrm{pH}$ 7.4, Plus $1 \%$ sucrose. Small blocks were postfixed in $1 \% \mathrm{OsO}_{4}$ in $0.1 \mathrm{M}$ phosphate buffer, $\mathrm{pH}$ 7.4, dehydrated in ethanol and embedded in polybed. Semithin $(0.5 \mu \mathrm{m}$-thick $)$ sections were stained with toluidine blue and examined light microscopically. Thin sections were stained with saturated uranyl acetate and lead citrate and examined with a JEM 1200EX-II electron microscope (JEOL, Japan) at $100 \mathrm{kV}$.

\section{Morphometry}

We took pictures of toluidine blue-stained sections on Days 1, 2, 4, 7 and 14 after ligation and analysed the intralobular distribution of apoptotic hepatocytes in two ways: 1) their incidence in necrotic and nonnecrotic areas and 2) that in central, intermediate and periportal zones of the lobule. We identified apoptotic hepatocytes light microscopically by either nuclear fragmentation or apoptotic bodies in the sections.

Firstly, we measured the sizes of necrotic areas, non-necrotic areas and whole areas of the sections. The numbers of apoptotic hepatocytes in each area were counted on ten sections at each time period and expressed as number of cells $/ \mathrm{mm}^{2}$ of the section. The frequency or density of apoptosis in necrotic areas 

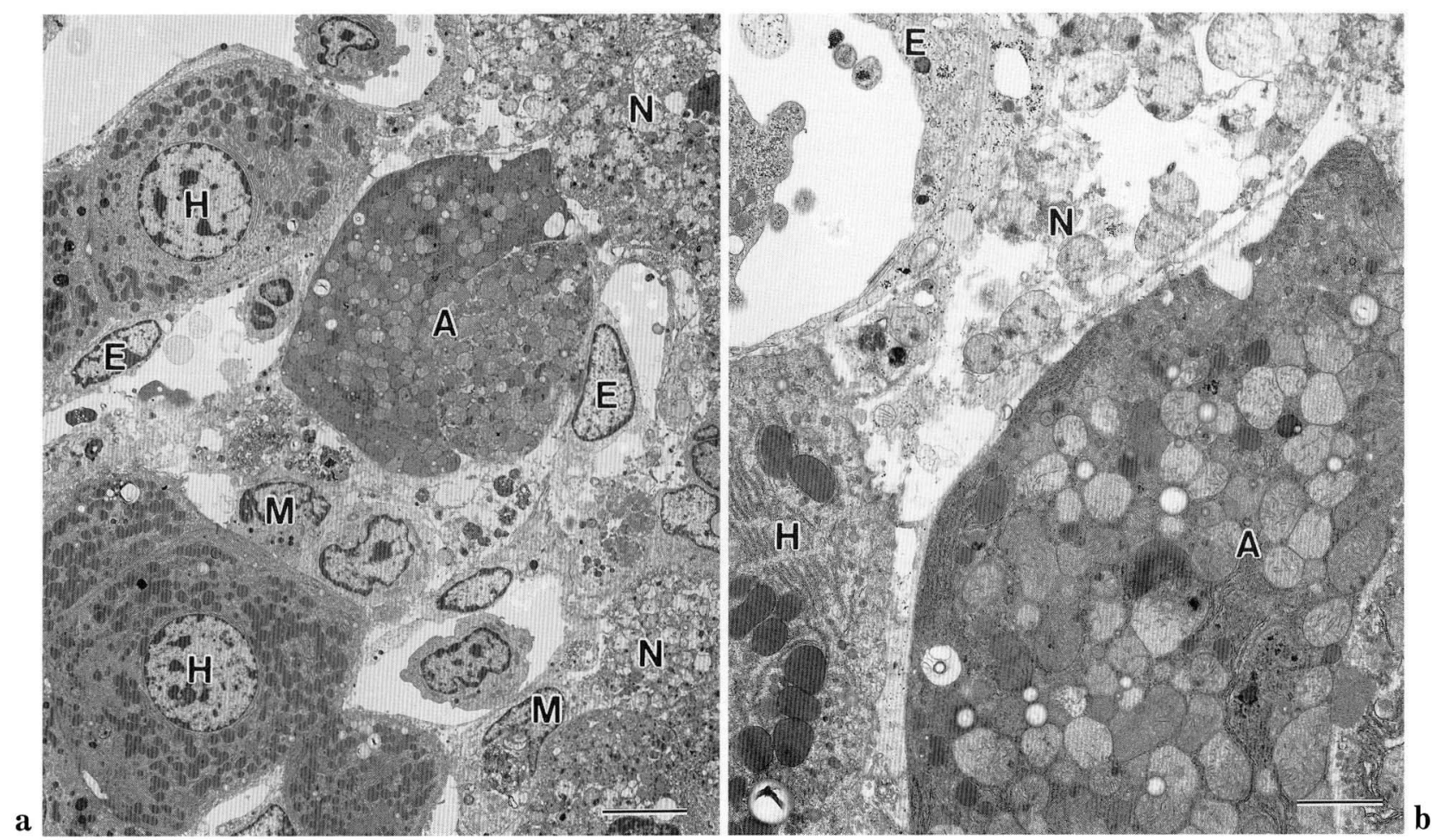

Fig. 10. Two days after ligation. a. An apoptotic hepatocyte $(A)$ exists between necrotic hepatocytes $(N)$ and intact ones $(H) . M$ macrophages, $E$ endothelial cells. Bar $=10 \mu \mathrm{m}$. b. shows a higher magnification of the portion where these three hepatocytes are joined. Note the different ultrastructural features of cell organelles among them. $\operatorname{Bar}=3 \mu \mathrm{m}$

and non-necrotic areas was then calculated and expressed as number of cells $/ \mathrm{mm}^{2}$ of necrotic areas or non-necrotic areas. In the necrotic areas, the apoptotic hepatocytes were usually distributed along the margin of necrotic areas as described in the Results, and the incidence of apoptosis in necrotic areas was expressed as the number of cells $/ \mathrm{mm}$ of circumference. The circumference was calculated by (total necrotic areas $\times \pi)^{1 / 2} \times 1 / 2$, regarding the total necrotic areas as one sphere.

Next, the lobular parenchymal mass in the ligated lobe on Day 4 was divided into 3 zones of equal width, referred to as the central, intermediate and periportal areas. The number of apoptotic cells was counted in each zone in 16 sections. The incidence of apoptosis was expressed as the number of cells $/ \mathrm{mm}^{2}$.

Furthermore, we made a diagram in which apoptosis and necrosis in five adjacent semithin sections (each about $15 \mu \mathrm{m}$ separation between slices) were overlayed.

\section{Statistical analysis}

Results were studied by analysis of variance (ANOVA).

\section{RESULTS}

\section{Weights of ligated and non-ligated liver lobes}

Ligated liver lobe weight decreased rapidly after operation (Fig. 1). It reached about one-half of its original weight on Day 2 and about one-third original weight on Day 4. It continued to decrease gradually until Day 7 , after which it decreased only slightly. On the other hand, non-ligated liver lobes increased in weight in a fashion opposite to that of ligated ones. The weight of these lobes reached twice its original weight on Day 2, three times original weight on Day 7 , and thereafter increased slowly until Day 14 . The weight of the liver as a whole was thus maintained near the baseline level after ligation.

\section{Light microscopic observation of lighted liver lobes}

One day after ligation, small necrotic areas appears in the central to intermediate zones of liver lobules, and became significantly larger by Day 2 (Fig. 2a). Sinusoidal endothelial cells and stellate cells in this 

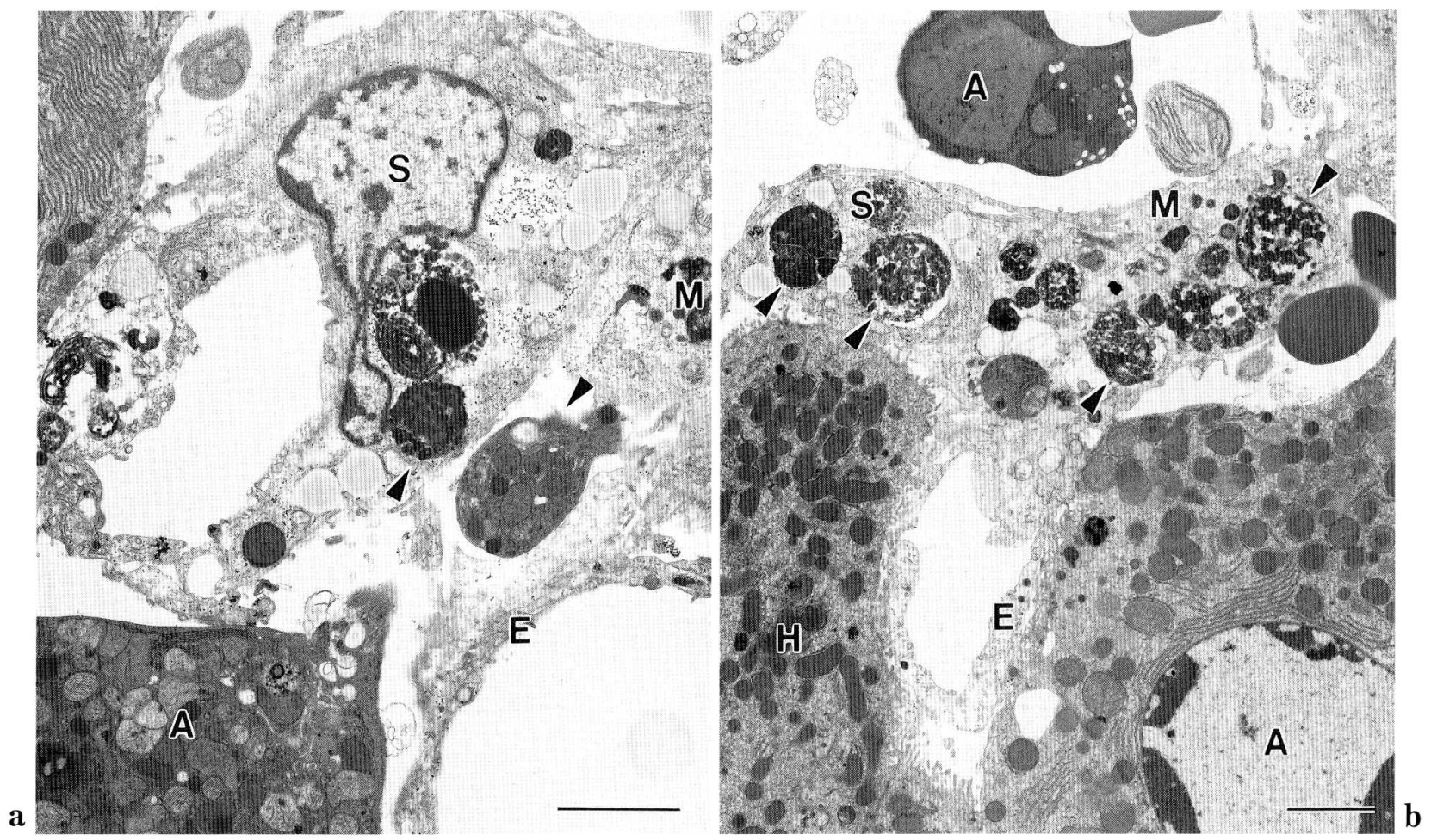

Fig. 11. Incorporatoin of apoptotic bodies of hepatocytes by neighboring cells 2 days after ligation. a. A stellate cell $(S)$ phagocitizing apoptotic bodies (arrowheads). There are no macrophages associated with an apoptotic hepatocyte $(A)$. $E$ endothelial cells. Bar $=3 \mu \mathrm{m}$. b. An apoptotic hepatocyte $(A)$ presumably at an early stage of apoptosis. It shows chromatin condensation of the nucleus and is devoid of microvilli on the luminal surface. Cell organelles are almost normal and the cytoplasm exhibits normal density. A macrophage $(M)$ does not yet extend cytoplasmic projections toward the apoptotic cell. A perisinusoidal stellate cell $(S)$ has also engulfed apoptotic bodies. Apoptotic bodies $(A)$ are also seen in the sinusoid. $H$ normal hepatocytes. $\mathrm{Bar}=3 \mu \mathrm{m}$

area were, however, intact. Macrophages or Kupffer cells in necrotic regions migrated extrasinusoidally and, as a result, no macrophages were seen inside the sinusoidal lumen of this area. We observed no particular accumulation of neutrophils nor lymphocytes around the necroses.

Necrotic hepatocytes were almost gone by Day 4 . These areas contained macrophages, stellate cells and a small number of collagen fibers. Although they included only a few necrotic hepatocytes, we have referred to these areas as necrotic areas for convenience in the following description. The necrotic areas became significantly reduced in size compared with that on Day 2 (Fig. 2b). By Day 7, it had become very limited in size, but still separated the hepatic cell cords (Fig. 2c). By Day 14, it almost disappeared, and the hepatic architecture was completely recovered without any fibrosis (Fig. 2d). The percentage of the necrotic area in the whole area of sections was $6.3 \%$ on Day $1,24 \%$ on Day $2,8.4 \%$ on Day $4,2.2 \%$ on
Day 7 and $0 \%$ on Day 14 .

During these periods, we often observed apoptotic hepatocytes. They exhibited the condensation of nuclear chromatin and normally stained cytoplasm in toluidine-biue stained specimens (Fig. 3). Some of them became apoptotic bodies which were spherical or oval cell bodies varying in size from $5-10 \mu \mathrm{m}$ in diamerter and densely stained.

\section{Kinetics and intralobular distribution of apoptotic hepatocytes in ligated lobes}

We counted apoptotic hepatocytes which exhibited nuclear chromatin condensation or apoptotic bodies on toluidine blue-stained sections at each time point after ligation. Apoptosis was present on Day 1, and subsequently increased rapidly in frequency, reaching a peak on Day 4 and decreasing by Day 7 (Fig. 4). We still observed a few apoptotic bodies on Day 14 .

We then studied the intralobular distribution of 
a

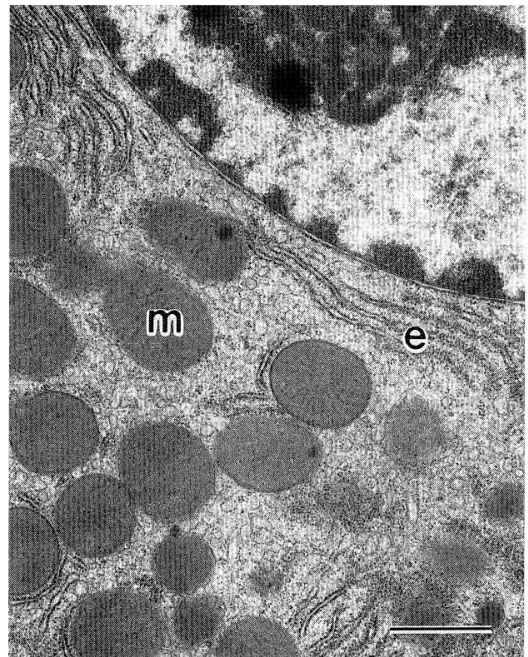

b
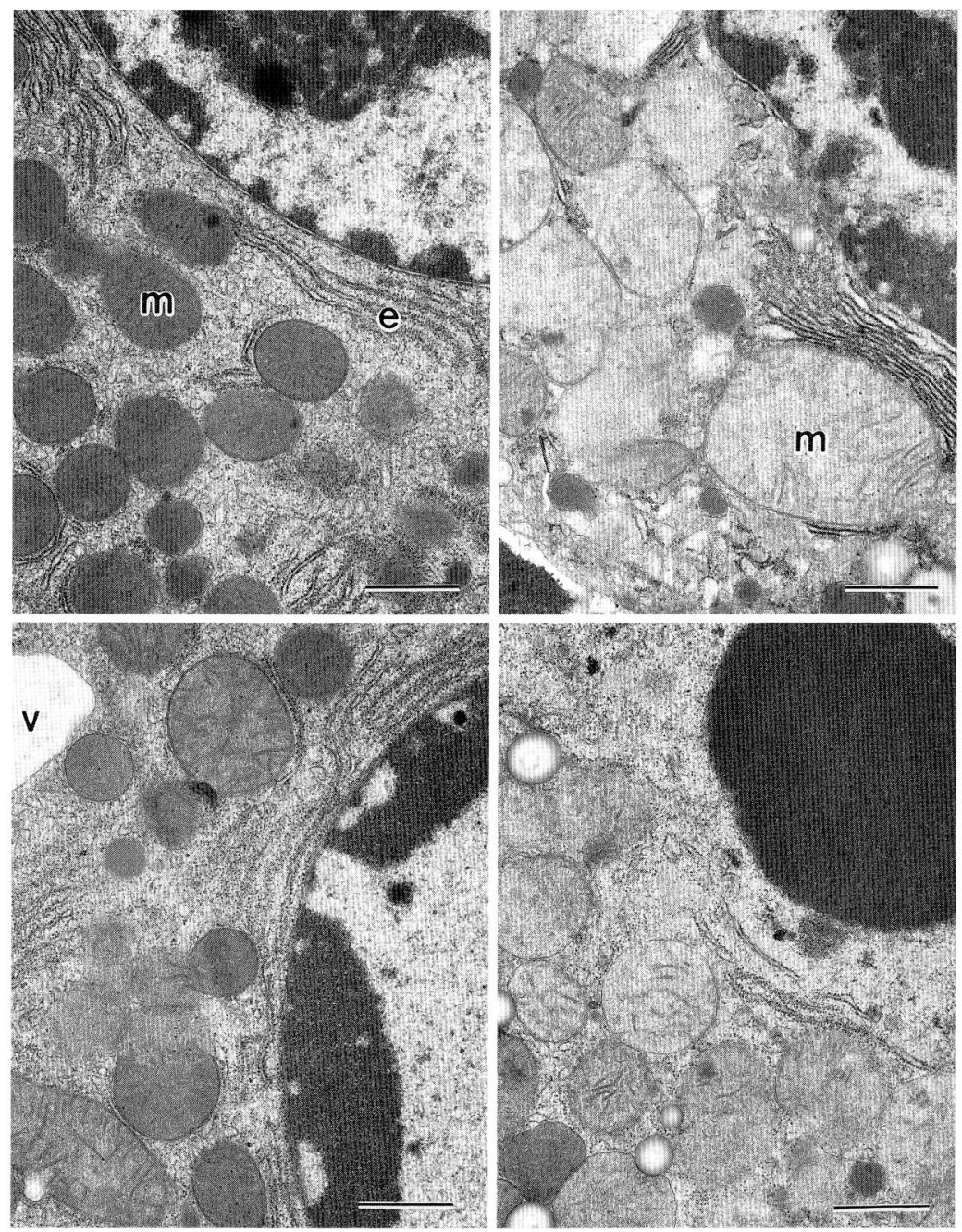

d

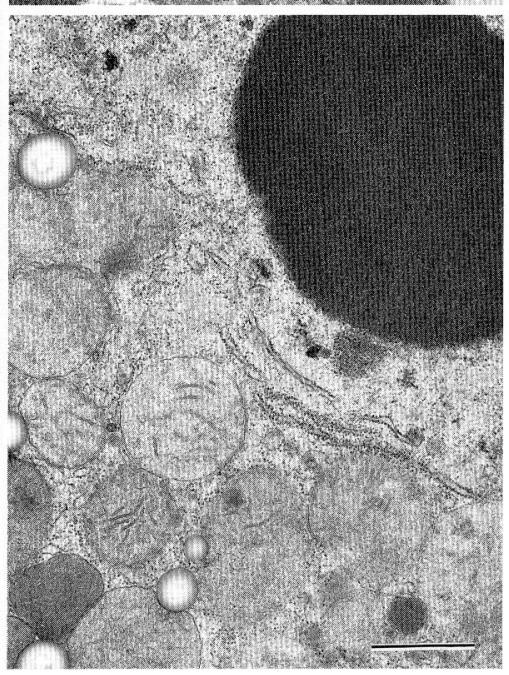

e c
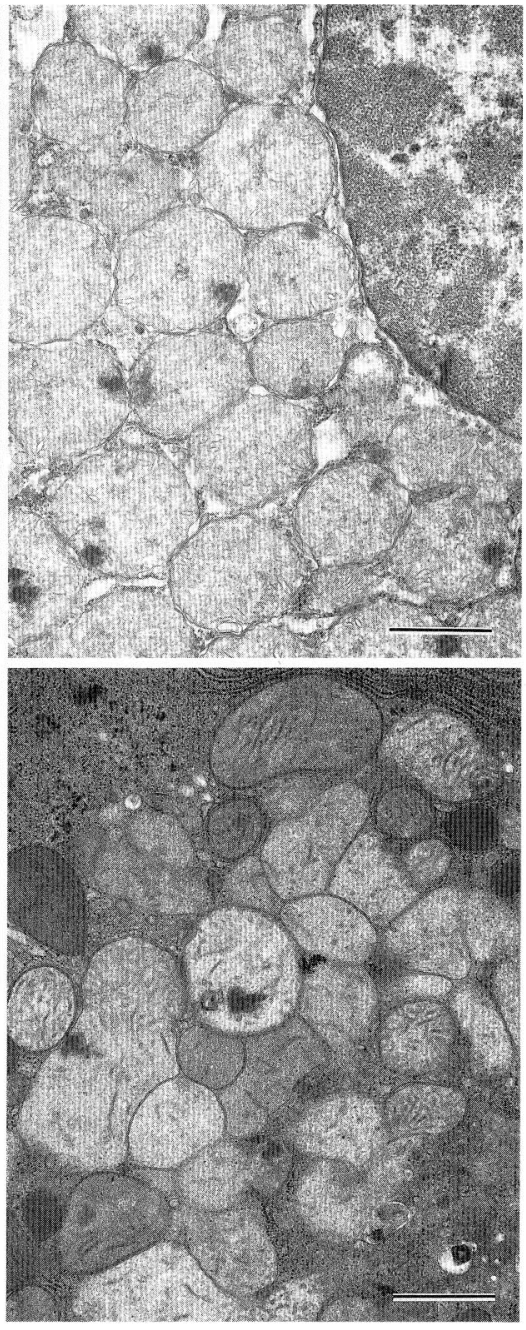

f

Fig. 12. Comparison of ultrastructural features of the nucleus and other cell organelles among normal hepatocytes (a), necrotic hepatocytes $(\mathbf{b}, \mathbf{c})$ and apoptotic hepatocytes $(\mathbf{d}-\mathbf{f})$ seen 2 days after ligation. Necrotic changes begin with the swelling of mitochondria $(m)(\mathbf{b})$. Nuclear and cytoplasmic matrices are then dissolved out and become pale. The cytoplasm is occupied by many fragmented mitochondria (c). In an early stage of apoptosis, chromatin condensation of the nucleus occurs with little change in cell organelles (d). As apoptotic changes proceed, mitochondria become pale and accummulated crowded, but mitochondrial cristae are obvious even in the late stage of apoptosis (f). Other cell organelles such as rough endoplasmic reticulum (e) show almost normal features. $v$ Vacuoles. Bars $(\mathrm{a}-\mathrm{f})=1 \mu \mathrm{m}$

apoptotic hepatocytes with particular reference to their relationship to the necrotic area. An example at Day 4 is shown in Figure 5. Apoptotic hepatocytes were distributed in both necrotic and non-necrotic areas. In necrotic areas, they tended to be present near non-necrotic areas. The incidence of apoptotic hepatocytes on Day 4 was much higher in the central areas than in the periportal areas of liver lobules (Fig. 6), probably because necrotic areas were more frequent in the central area. Figure 7 shows the time course of the numbers of apoptotic hepatocytes existing in necrotic areas and non-necrotic areas, expressing these as the number of cells per unit square of sections. Apoptotic hepatocytes in necrotic areas appeared on Day 1, and reached a peak on Day 2 when necrotic areas reached their maximum to there after decline as necrotic areas reduced in size. On the other hand, apoptosis in non-necrotic areas increased 

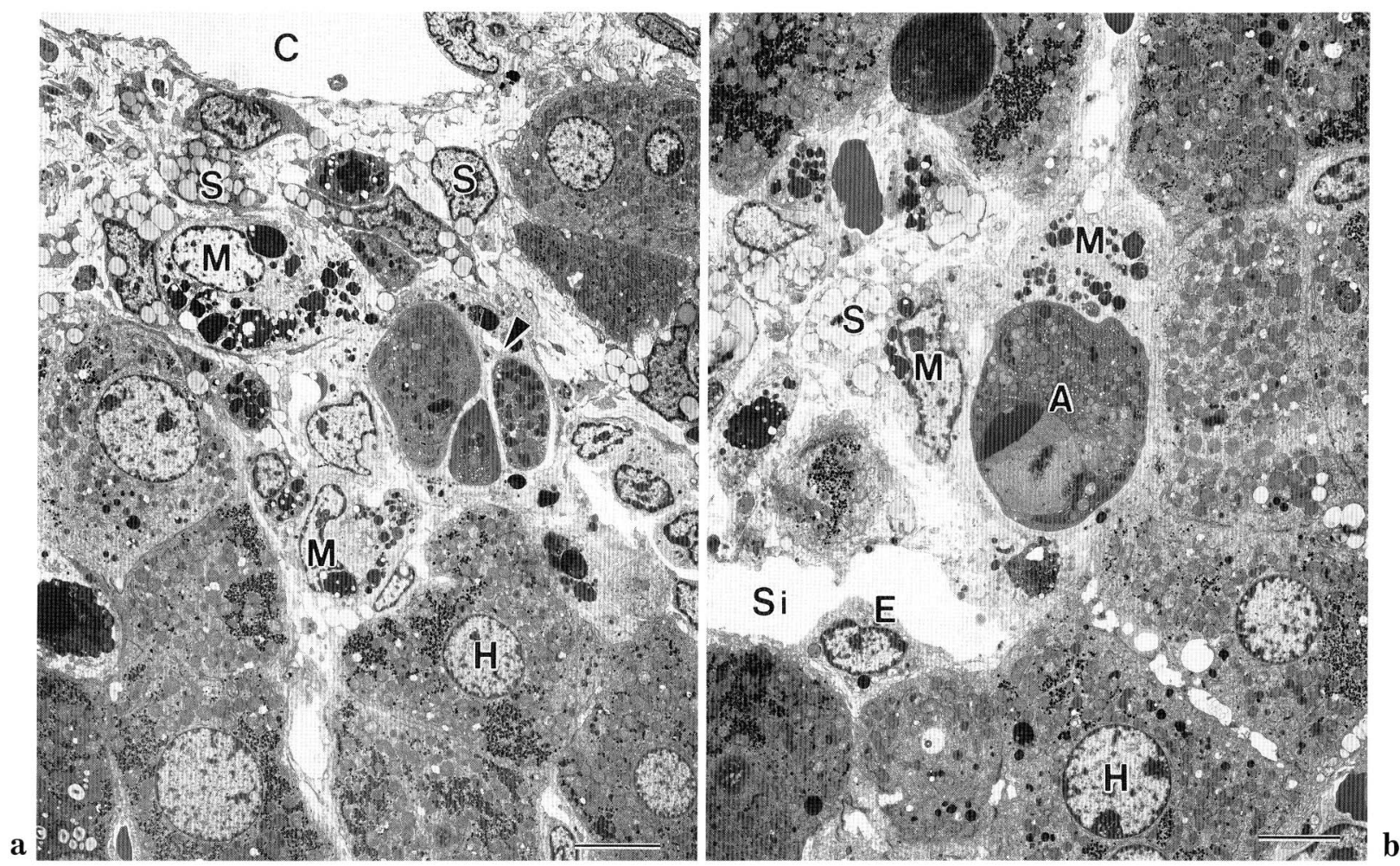

Fig. 13. Apoptotic hepatocytes ( $A$ or arrowhead) in the necrotic areas which consist of stellate cells $(S)$ and extrasinusoidally migrating macrophages $(M) 7$ days after ligation. $H$ normal hepatocytes, $C$ central veins, $S i$ sinusoids. Bar (a) $=10 \mu \mathrm{m},(\mathrm{b})=5 \mu \mathrm{m}$

significantly on Day 4, reached a peak on Day 7 and dacreased in number significantly by Day 14 . The cell numbers counted here depended on the width of the area, so in order to eliminate the size factor for each area, we calculated the frequency of apoptotic cells per unit square of each area (Fig. 8a, b). Frequency, or density, of apoptotic hepatocytes was high on Day 2 and 4 in necrotic areas (Fig. 8a), while it was high on Days 4 and 7 in non-necrotic areas (Fig. 8b).

\section{Electron microscopic observations of apoptotic hepatocytes in ligated liver lobes}

We therefore next examined the ultrastructure of apoptotic hepatocytes on Day 2 and Day 7. On Day 2, massive hepatocytic necrosis was noted. Necrotic hepatocytes showed swollen mitochondria with disappearing cristae (Fig. 9) and then lost the cytoplasmic matrix (Fig. 10). Sinusoidal lining structures such as stellate cells and sinusoidal endothelial cells exhibited normal features (Fig. 9). Macrophages had migrated extrasinusoidally and digested debris from degenerated hepatocytes. Apoptosis was usually present at the boundary between necrosis and intact areas (Fig. 10). Apoptotic hepatocytes and necrotic hepatocytes often existed side by side (Fig. 10).

At the beginning of apoptosis, hepatocytes exhibited almost normal features of cell organelles except for nuclear chromatin condensation and the disappearance of microvilli and that they were not yet surrounded by cytoplasmic projections of macrophages (Fig. 11a). Apoptotic bodies separated from the cell were incorporated by neighboring cells such as macrophages (Fig. 11a), stellate cells (Fig. 11a, b), endothelial cells and hepatocytes. Phagocytosed apoptotic bodies became condensed due to digestion by lysosomal enzymes.

Electron microscopically, apoptotic hepatocytes exhibited features distinct from those of necrotic hepatocytes. Figure 12 shows the sequence of apoptosis and necrosis of hepatocytes observed on Day 2. Necrosis began with mitochondrial swelling but without any change in nuclear chromatin (Fig. 12b). As it proceeded, the mitochondrial matrix was dissolved out and cristae could not be obviously recognized (Fig. 12c). Nuclear chromatin was still scattered inside the nucleus, but the nuclear matrix had been lost or become pale (Fig. 12c). On the other hand, 

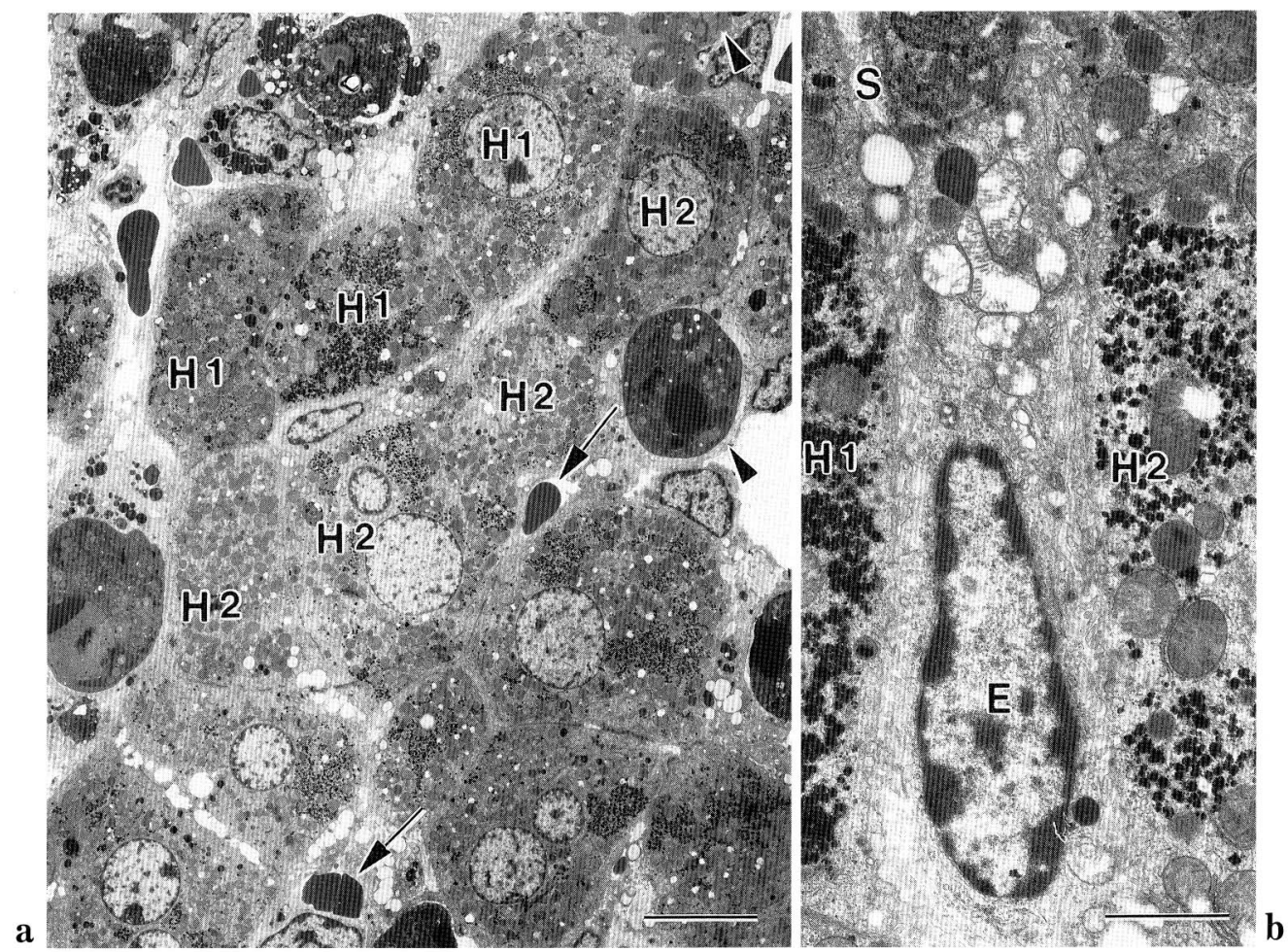

Fig. 14. Central to intermediate zones of a hepatic lobule 7 days after ligation. A central vein exists toward the left side of this figure. Hepatocytes are packed closely with narrow sinusoidal lumens (arrows). Two parallel hepatic cords ( $H 1, H 2)$ are recognized and an endothelial cell $(E)$ is interposed between them (higher magnification is shown in $\mathbf{b}$. There is no obvious sinusoidal lumen. Arrowhead apoptotic hepatocytes, $S$ stellate cells. Bar (a)= $10 \mu \mathrm{m},(\mathrm{b})=2 \mu \mathrm{m}$

in apoptotic cells, nuclear change preceded cytoplasmic changes. Apoptosis began with the condensation of chromatin and loss of microvilli with no evidence of degenerating cell organelles such as the swelling of mitchondria (Fig. 12d). As it advanced, mitochondria became somewhat swollen, but the cristae never disappeared (Fig. 12e). Finally, the mitchondria became very crowded in the densely stained cytoplasm (Fig. 12f).

On Day 7, apoptotic hepatocytes often faced necrotic areas which were located near central veins and consisted of stellate cells and macrophages (Fig. 13). They were also found among intact hepatocytes. After necrotic hepatocytes had undergone dissolution, hepatocytes were located more peripherally in the lobule than the necrotic area and were densely packed in the periphery (Fig. 14), since no regeneration of hepatocytes was occurring. We often observed that endothelial cells and/or stellate cells which did not form obvious sinusoidal lumina were interposed between two parallel hepatic cell cords (Figs. 14-16). Apoptotic hepatocytes were observed nearby such closed sinusoids (Figs. 15, 16) and sinusoidal endothelial cells often phagocytosed apoptotic bodies (Fig. 16).

\section{DISCUSSION}

The present study has demonstrated from the histologic and kinetic aspects that there are two phases of apoptosis of hepatocytes in the course of volume reduction of liver lobes after portal branch ligation: in the first phase on Days 1-4 when coagulation necrosis of hepatocytes is apparent, apoptosis of hepatocytes is induced in the periphery of the necrotic area; in the second phase on Days 4-7 when necrotic areas are diminishing, apoptosis occurs in no relation to necroses but does so among viable hepatocytes.

In this study, portal-deprived liver lobes underwent progressive atrophy with almost the same kinetics as reported by RozGA et al. (1986). Weight reduction of ligated liver loves was principally the consequence of hepatic necrosis. It was mostly completed by Day 4 , during which time about $90 \%$ of final reduction occur- 


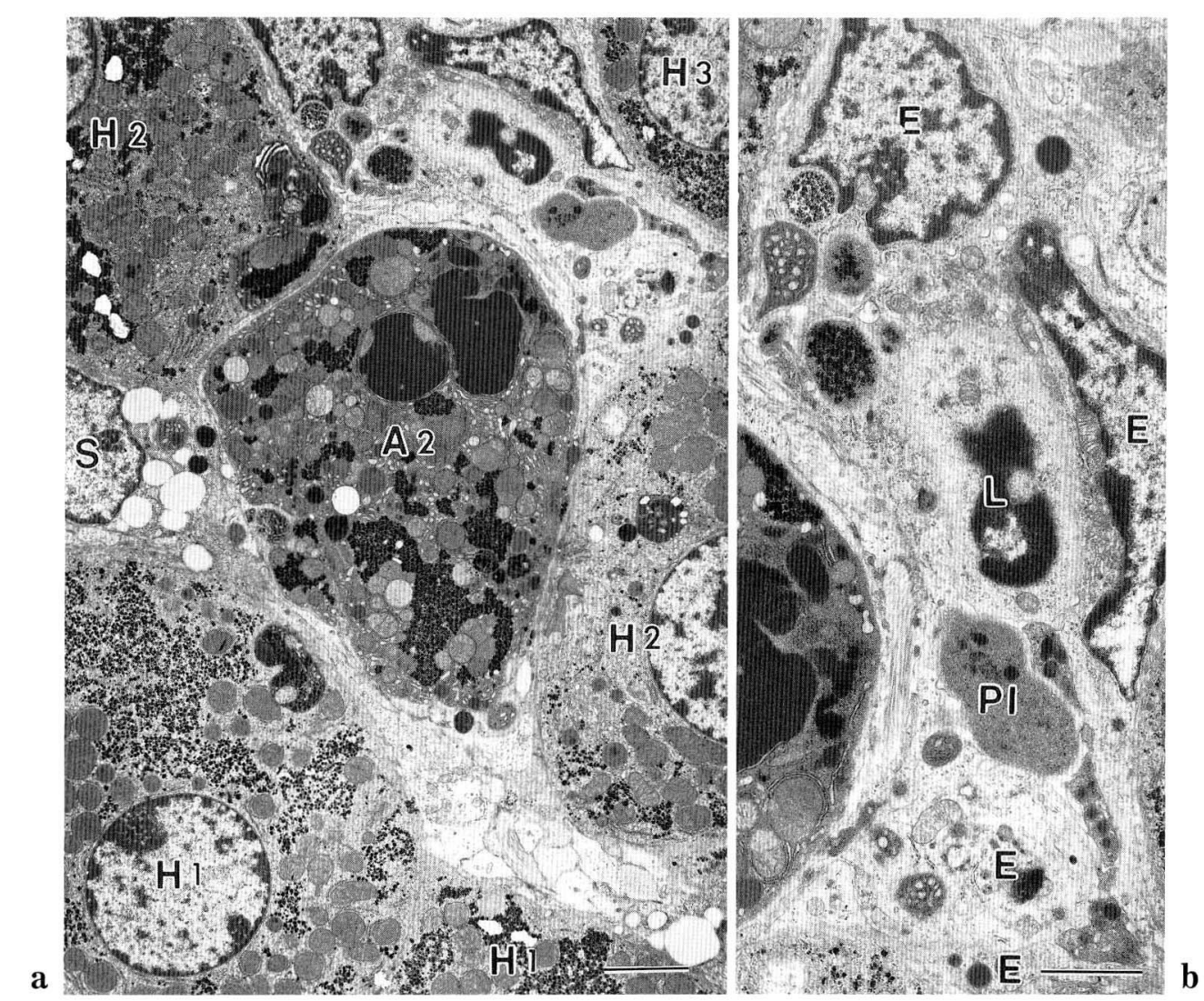

Fig. 15. An apoptotic hepatocyte $(A 2)$ between normal hepatocytes $(H)$ on Day 7 . Three parallel hepatic cell cords (H1, H2 and A2, H3) appear without any obvious sinusoidal lumen between them. b. A higher magnification of the upper portion of $\mathbf{a}$. This sinusoid is occluded by platelets $(P l)$ and a lymphocyte $(L)$ and has no open space. $E$ endothelial cells, $S$ stellate cells. Bar (a) $=3 \mu \mathrm{m},(\mathrm{b})=2 \mu \mathrm{m}$

red, and massive necrosis of hepatocytes and elimination of degenerated cells were observed. Massive hepatocytic necrosis appears to be due to the sudden and significant decrease in blood flow and resulting pronounced hypoxia which follows portal vein ligation. The findings that apoptotic hepatocytes are localized near the borders between necrotic areas and normal areas and that the incidence of apoptosis in necrotic areas almost parallels that of hepatocytic necrosis suggests that a close relationship exists between apoptosis and necrosis. It is also reported in the tumor nodule that apoptosis is enhanced near the interface between viable tissue and an area of necrosis (SEARLE et al., 1975). Although apoptotic hepatocytes were observed in the vicinity of necrotic hepatocytes, the sequences of cellular untrastructural changes characteristic of apoptosis and necrosis were distinct.

Various stimuli such as those mediated by Fas ligand (Rouvier et al., 1993) have been reported to cause apoptosis. In this study, however, we rarely observed any adherence of lymphocytes, which may have Fas ligand molecules (SuDA et al., 1993), to apoptotic hepatocytes at the beginning of apoptosis. The fact that apoptotic cells were surrounding necrotic areas suggests that apoptosis may be caused by hypoxia as is also the case for necrosis; if so, severe ischemia induces necrosis while mild ischemia induces apoptosis as descrived by KeRR (1971). There are only a few reports on the relationship of apoptosis with oxygen. Recentry, delayed neuronal death induced by transient hypoxia in hippocampus (KIRINO, 1982; KIRINO and SANO, 1984) has been revealed to apotosis (NiTATORI et al., 1995). MCConkey et al. (1988) have demonstrated the relationship of endogeneous endonuclease activity, which is involved in apoptosis, with oxidative stress in hepatocytes. The Molecular mechanism by which a quantitative difference of oxygen concentration in the blood flow can induce qualitatively different process of cell death in the hepatocytes is to be further investigated. 


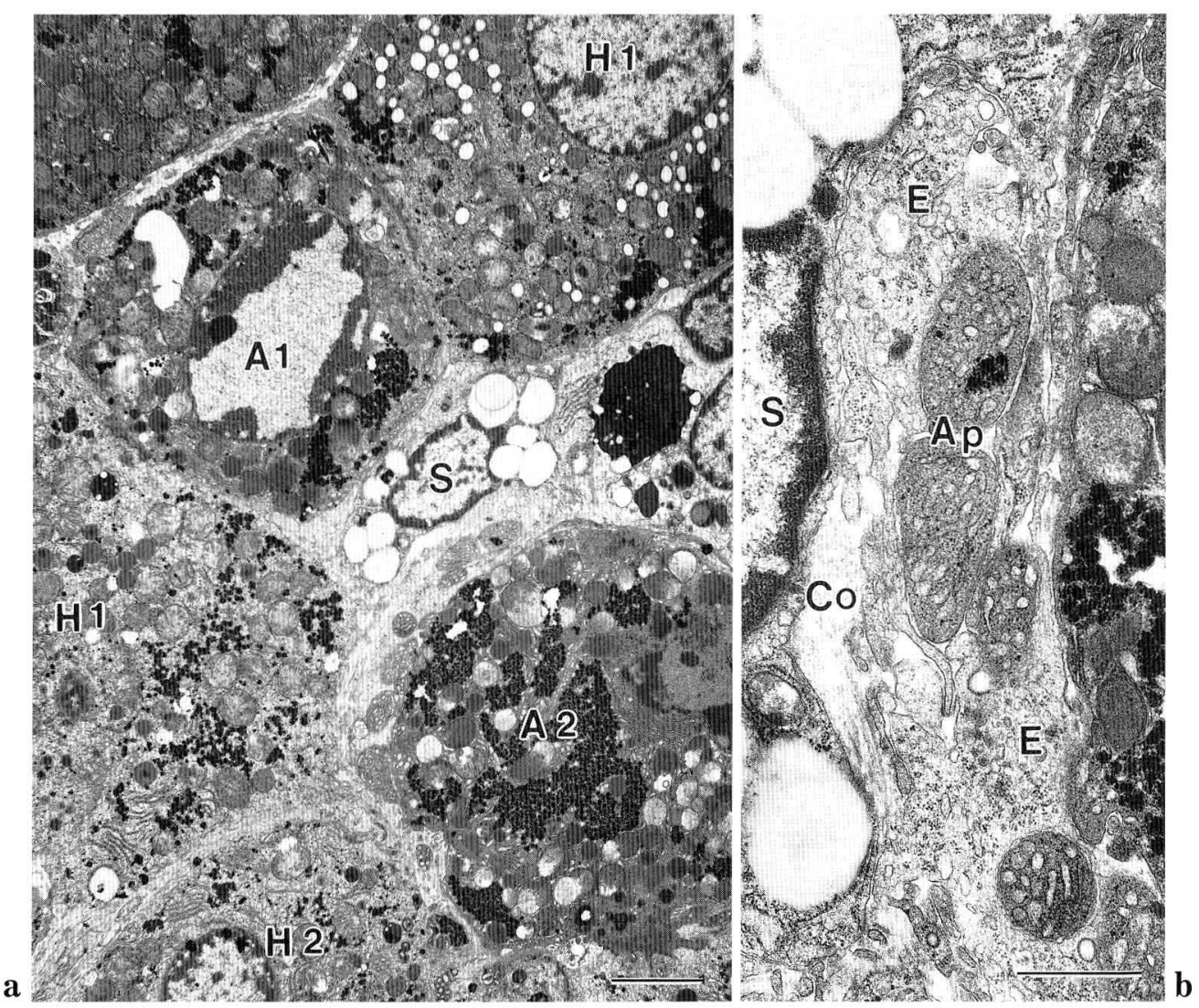

Fig. 16. Apoptotic hepatocytes $(A 1, A 2)$ between normal hepatocytes $(H)$ on Day 7 . The sinusoidal lumen between two hepatic cell cords ( $H 1$ and $A 1, H 2$ and $A 2$ ) becomes very narrow and is occluded with apoptotic bodies $(A p)$ as shown in b. S stellate cells, $E$ endothelial cells, $C o$ collagen fibers. $\operatorname{Bar}(\mathrm{a})=3 \mu \mathrm{m}$, (b) $=1 \mu \mathrm{m}$

Our present findings also demonstrated that apoptosis plays a role in the reconstruction of hepatic cell cords on Days 4-7 after portal branch ligation, as shown in Figure 17. Since the hepatic cell cords diverge toward the portal area, they have been drawn as Y-shaped in Figure 17. After degenerating hepatocytes have been removed, hepatocytes are not supplied to the necrotic areas by regeneration of hepatocytes around these areas. We did not observe here any mitoses of hepatpcytes in the ligated liver loves; this result is in accordance with a previous study (RozGS et al., 1986). Instead, the necrotic areas are compressed by and filled with hepatocytes located more peripherally in the lobule than the necrotic area. As hepatocytes approach the central zone of the liver lobule, neighboring hepatic cell cords come closer to each other and finally become densely packed, compressing and finally occluding the interposed sinusoidal lumen. The narrowing or occulusion of the sinusoidal lumen may also result from the reduced arterial inflow to the ligated lobes due to the contrac- tion of arterial branches (RozGA et al., 1986). A Similar slitlike appearance or blind lumen of sinusiods have also been reported in proliferating disorders such as benign liver cell adenoma (BioulaCSAGE et al., 1988). The "combined hepatic cell cords" formed in this fashion are too thick to be supplied with sufficient oxygen and nutrients by sinusodial blood flow. Apoptpsis of the hepatocytes seen in such areas is considerd to contribute to the reduction of the thickness of "combined hepatic cell cords".

Apoptosis also occurred in those hepatocytes which faced the necrotic area near the central vein on Day 7; such hepatocytes are distant from the sinusoidal lumen and are insufficiently supplied with oxygen from the blood flow. The initiating stimulus for apoptosis both in the "combined hepatic cell cords" and near the necrotic area therefore appears to be mild ischemia, as was the case on Days 1-4. In order to eliminate excess hepatocytes and counterbalance the cell number to the sinusoidal blood flow, apoptotic change occurs in the hepatocytyes during this 


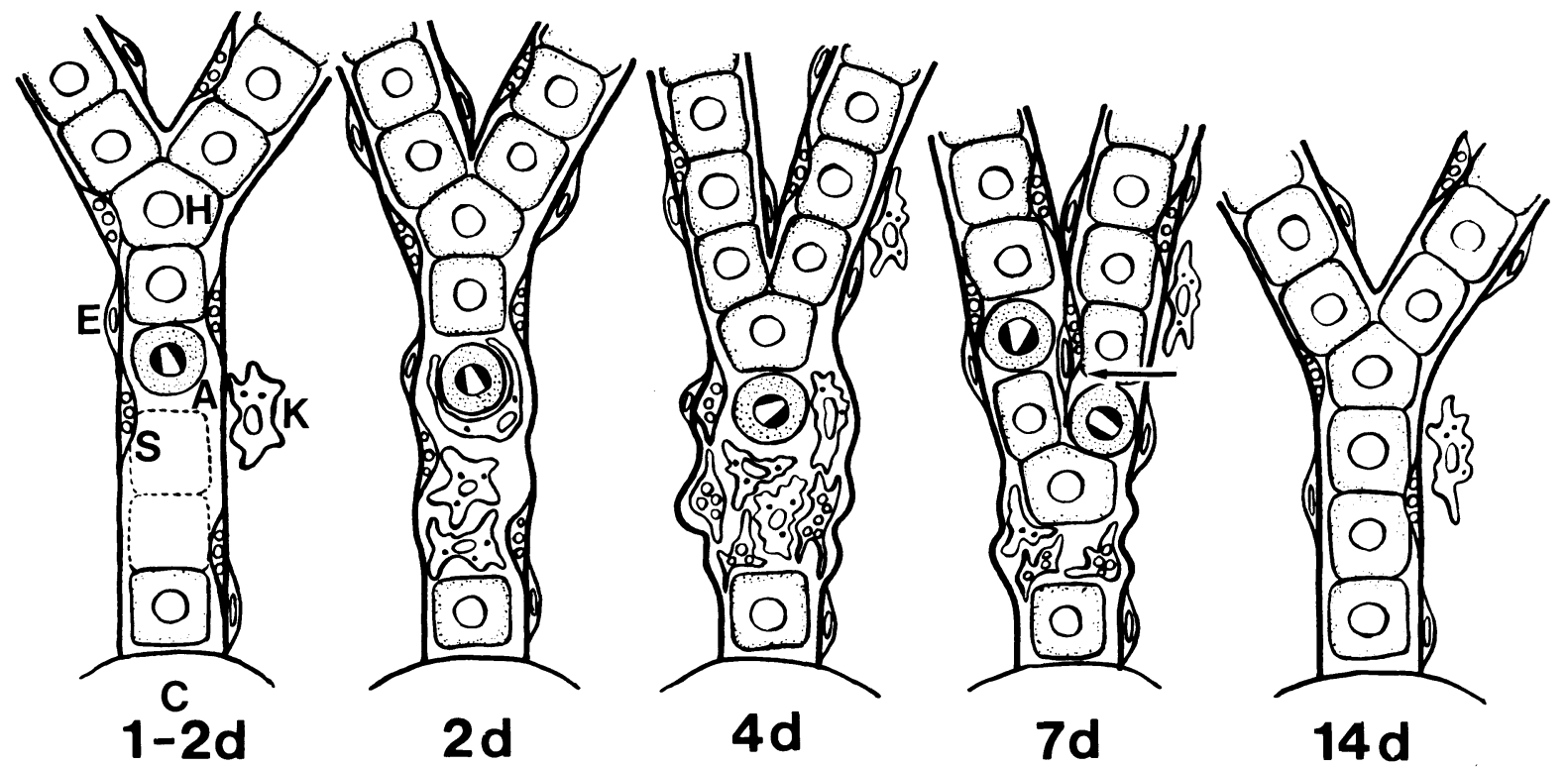

Fig. 17. Diagram representing the generation of apoptotic hepatocytes in the course of reducing the size of the liver lobule after portal branch ligation. As hepatic cell cords diverge toward the portal area, they are drawn as Y-shaped. After necrotic hepatocytes are removed, necrotic areas consist mainly of stellate cells and macrophages. Apoptosis of hepatocytes occurs at the boundary area between necrotic and normal areas on Days 1-4. The necrotic areas are then pressed by the hepatocytes located more peripherally in the lobule than the necrotic area. Sinusoidal lumen between neighboring hepatic cell cords becomes narrow and is finally occluded. Excess hepatocytes which cannot be supplied with sufficient oxygen or nutrients are eliminated by apoptosis on Days 4-7. At 14 days, normal hepatic architecture is recovered. $A$ apoptotic hepatocytes, $H$ normal hepatocytes, $S$ stellate cells, $E$ endothelial cells. $C$ central veins.

time period. The slight decrease in weight of ligated liver loves during the period 4 to 7 days after ligation appears to have been due to cell death by apoptosis.

In conclusion, the apoptosis of hepatocytes induced after portal branch ligation contributes not only to the volume reduction of the liver lobule but also to the reconstruction of the hepatic plate architecture.

Acknowledgements. The authors express thier sincere thanks to Dr. Norifumi KawADA, Osaka City University Medical School, and Dr. Yoshiyuki TAKEI, Osaka University Medical School, for their valuable comments on this work.

\section{REFERENSES}

Bioulac-Sage, P., M. E. Lafon, B. Le Bail, A. Boulard, L. Dusuisson, A. Quinton, H. Lamouliatte, J. SariC and C. BALABAUd: Ultrastructure of sinusoids in liver disease. In: (ed. by) P. Bioulac-SAGE and C. BALABAUD Sinusoids in humman liver: health and disease. Kupffer Cell Foundation, Rijswijk, 1988 (p. 223-278).
KERR, J. F. R.: A histochemical study of hypertrophy and ischaemic injury of rat liver with special reference to changes in lysosomes. J. Pathol. Bacteriol. 90: 419-435 (1965).

KERR, J. F. R.: Shrinkage necrosis a distinct mode of cellular death. J. Pathol. 105: 13-20 (1971).

Kerr, J. F. R. A. H. Wyllie and A. R. Currie: Apoptosis A basic biological phenomenon with wide ranging implications in tissue kinetics. Brit. J. Cancer 26: 239257 (1972).

Kinoshita, H., K. Sakai, Hirohashi, S. Igawa, 0. YAMASAKI and S. Kubo: Preoperative portar vein embolization for hepatocellilar carcinoma. world J. Surg. 10: 803-808 (1986).

Kinoshita, H., K. Hirohashi and S. Kubo: Preoperative portal vein embolization for hepatocellular carcinoma. In: (ed. by) $T$. TOBE et al.: primary liver cancer in Japan. Springer-Verlag, Tokyo, 1992 (p. 283-290).

KIRINo, T.: Delayed neuronal death in the gerbil hippocampus following ischemia. Brain Res. 239: 57-69 (1982).

KIrINo, T. and K. SANo: Fine structural nature of delayed neuronal death following ischemia in the gerbil hippocampus. Acta Neuro. Pathol. (Berl.) 62: 209-218 (1984). 
McConkey, D. J., P. Hartzell, P. Nicotera, A. H. WylliE and S. ORRENIUS: Stimulation of endogenous endonuclease activity in hepatocytes exposed to oxidative stress. Toxicol. Lett. 42: 123-130 (1988).

Nitatori, T., N. SATO, S. Waguri, Y. Karasawa, H. ArLki, K. Shibanai, E. Kominami and Y. UChiYama: Delayed neuronal death in the CA1 pyramidal cell layer of the gerbil hippocampus following transient ischemia is apoptosis. J. Neurosci. (1995, in press).

Rouvier, E. M.-F. Luciani and P. Golstein : Fas involument in $\mathrm{Ca}^{2+}$-independent $\mathrm{T}$ cell-mediated cytotoxicity. J. Exp.Med. 177: 195-200 (1993).

Rozga, J., B. Jeeprsson and S. Bengmark: Portal branch ligation in the rat. Reevaluation of model. Amer. J. Pathol. 125: 300-308 (1986).

Schalm, L., H. R. BaX and B. J. Manses: Atrophy of the liver after occlusion of the bile ducts or portal vein and compensatory hypertrophy of the unoccluded portion and its clinical importance. Gastroenterology 31: 131155 (1956).

Searle, J., T. A. Lawxon and P. J. Aвbott: An electronmicroscope study of the mode of cell death induced by cancer chemotherapeutic agents in populations of proliferating normal and neoplastic cells. J. Pathol. 116: 129-138 (1975).
Steiner, P. E. J. B. Martinez: Effects on the rat liver of bile duct, portal vein and hepatic artery ligations. Amer. J. Pathol. 39: 257-289 (1961).

Suda, T., T. Takahashi, P. Golstein and S. Naagyta: Molecular cloning and expression of the Fas ligand, a novel member of tumor necrosis factor family. Cell 75: 1169-1178 (1993).
Dr. Kazuo IKedA Department of Anatomy Osaka City University Medical School 1-4-54 Asahimachi, Abeno-ku Osaka, 545 Japan

池田一雄

545 大阪市阿部野区旭町 1-4-54

大阪市立大学医学部 第二解剖学教室 